\title{
STUDI PENGENDALIAN BANJIR SUNGAI KALIDAWIR TULUNGAGUNG
}

\author{
Bambang Sarwono, Mohammad Bagus Ansori, dan Dian Ayu Ratnasari \\ Jurusan Teknik Sipil, Fakultas Teknik Sipil dan Perencanaan, Institut Teknologi Sepuluh Nopember (ITS) \\ Jl. Arief Rahman Hakim, Surabaya 60111 \\ E-mail:dianayuratnasari@gmail.com
}

\begin{abstract}
Abstrak- Studi Pengendalian Banjir Sungai Kalidawir Tulungagung merupakan studi penanggulangan terhadap masalah banjir yang terjadi di wilayah Kalidawir. Saat musim penghujan datang, terjadi debit banjir yang besar menyebabkan beberapa wilayah sepanjang kalidawir rawan terhadap banjir bandang tadi. Hal ini terjadi karena kapasitas penampang dari hulu yang semula mampu menampung debit banjir kemudian berubah semakin mengecil karena berada di dekat sawah dan pemukimam penduduk. Karena itu diperlukan analisa hidrologi untuk mengetahui debit banjir rencana dan analisa hidrolika dengan Hec.Ras 4.1.0 untuk mengetahui kapasitas sungai Kalidawir eksisting.

Upaya Pengendalian banjir yang dilakukan dengan cara normalisasi. Upaya Normalisasi sejauh 8767.5 meter dilakukan dengan beberapa pekerjaan seperti pengerukan sedimen, perencanaan krib, perencanaan ambang (Ground sill) ditambah analisa hidrolika perubahan penampang.
\end{abstract}

Kata Kunci : Banjir, Bandang, Normalisasi, Sungai.

\section{PENDAHULUAN}

Sungai Kalidawir merupakan salah satu sungai yang melewati wilayah tulungagung bagian selatan. Sungai kalidawir memiliki luas DAS 296,40 $\mathrm{Km}^{2}$ dengan panjang sungai mencapai 37 Kilometer. Aliran sungai kalidawir dari hulu dimulai dari Desa Banyuurip sampai daerah hilir yang terletak di Desa Kendal bulur. Bagian hilir dari sungai kalidawir ini nantinya bermuara pada sungai Parit Agung.

Daerah di sekitar Sungai Kalidawir merupakan wilayah yang rawan bencana. Saat musim kemarau dimanfaatkan sebagai pemasok kebutuhan air irigasi disamping fungsi utamanya sebagai afvour. Permasalahan di lapangan menunjukkan bahwa saat musim penghujan tiba, penampang sungai tidak mampu menampung curah hujan yang terjadi. Beberapa kejadian banjir besar pun menyebabkan beberapa wilayah sepanjang sungai Kalidawir terkena dampak limpasan yang merugikan.

Beberapa daerah yang pernah terkena dampak banjir merupakan daerah pemukiman penduduk, sawah dan lahan produktif lainnya. Kerugian yang diakibatkan oleh limpasan banjir tentunya mengganggu aktivitas ekonomi masyarakat dan kerugian materiil yang besar. Untuk menanggulangi pengendalian daya rusak ini, terlebih dahulu perlu dipahami karakteristik dari ruas sungai yang ditinjau sehingga diperoleh alternatif optimum dalam perbaikannya. Manfaat dari Studi Pengendalian Banjir Sungai Kalidawir ini diharapkan dapat diketahui penyebab terjadinya limpasan air banjir yang sering terjadi di daerah sungai Kalidawir.

Dengan melihat kerusakan yang terjadi, maka diperlukan perhatian dan upaya pengendalian daya rusak akibat banjir secara komprehensif. Hal ini perlu dilakukan untuk menjaga kondisi sungai Kalidawir sesuai dengan kapasitas dan fungsinya kembali.

\section{METODOLOGI}

Proses pengerjaan tugas akhir ini ditampilkan dalam sebuah alur pengerjaan tugas akhir yang dapat dilihat dari diagram alir dibawah ini : 


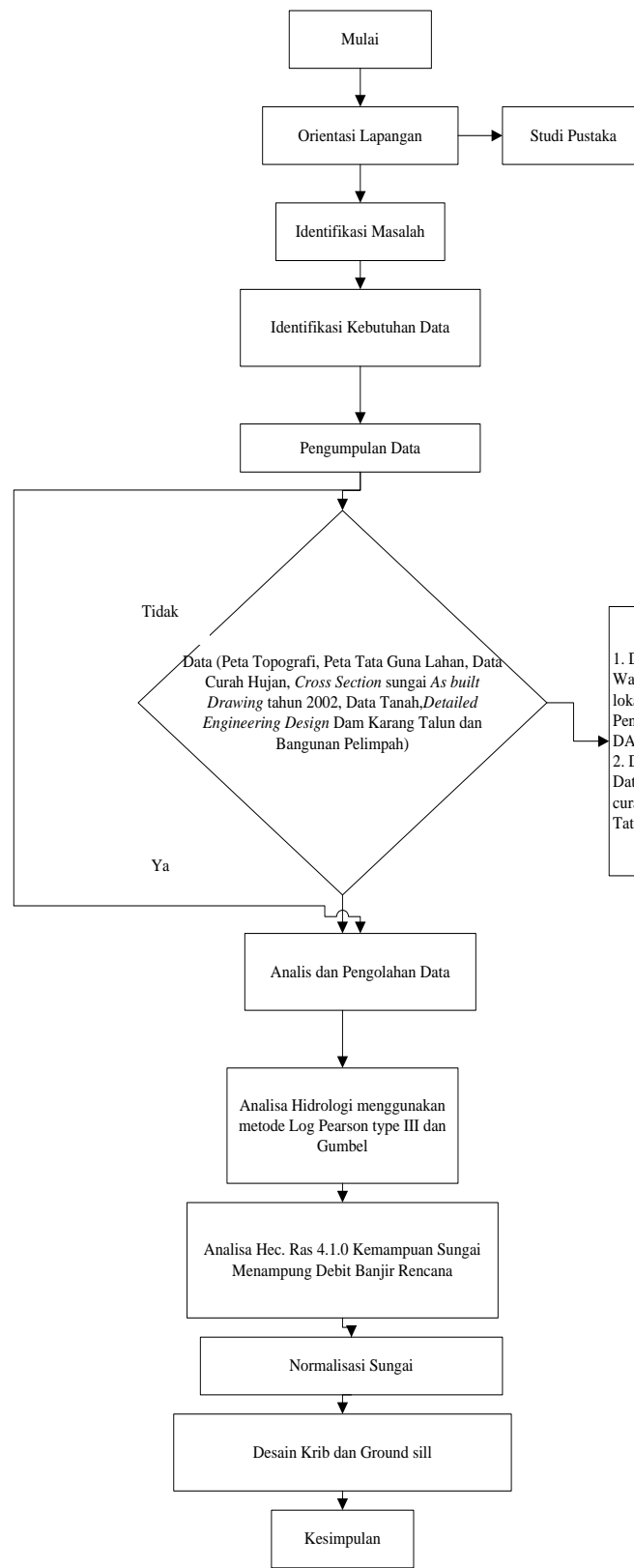

Gambar 1. Diagram Alir Pengerjaan Tugas

Akhir

Penjelasan dari diagram alir serta metodologi secara rinci terkait penelitian dapat dilihat di Ratnasari, Dian Ayu (2013) [13].

\section{HASIL DAN PEMBAHASAN}

\subsection{Konsep Pengendalian Banjir}

Pengendalian Banjir disini dimaksudkan untuk memperbesar kapasitas Kalidawir berupa normalisasi sungai. Normalisasi dilakukan dengan melakukan pelebaran penampang melintang sungai serta mengatur kemiringan memanjang sungai. Hal ini dilakukan guna menambah kapasitas kali Kalidawir dalam menampung debit banjir rencana maupun keperluan lain seperti air irigasi. Dikarenakan keterbatasan crosssection sungai maka saluran pembuang(drainase lokal) diabaikan. Aspek sosial, ekonomi dan lingkungan diabaikan.

\subsection{Analisa Frekuensi}

Tabel 3.1 Curah Hujan Rata-rata Maksimum yang telah diurutkan dari terbesar ke terkecil

$\begin{array}{lll}\text { No } & \text { Tahun } & \bar{X} \\ 1 & 2000 & 172.406 \\ 2 & 2004 & 143.869 \\ 3 & 2005 & 143.869 \\ 4 & 2006 & 132.869 \\ 5 & 2002 & 125.468 \\ 6 & 2001 & 125.468 \\ 7 & 2003 & 96.368 \\ 8 & 2010 & 93.081 \\ 9 & 2008 & 90.033 \\ 10 & 2009 & 79.755 \\ 11 & 2013 & 68.418 \\ 12 & 2012 & 61.473 \\ 13 & 2007 & 61.333 \\ 14 & 2011 & 62.6 \\ 15 & 1999 & 55.501\end{array}$

Sumber : Dinas Pengairan Kabupaten Tulungagung

Berikut beberapa nilai parameter-parameter statistic yang dimiliki data hujan diatas adalah : Nilai rata-rata $(\bar{X})$

$$
\bar{X}=\frac{\Sigma X}{n}=\frac{15125014}{15}=100.833
$$

Deviasi (standart deviation)

$$
\mathrm{Sd}=\sqrt{\frac{\sum \log (X-X r)^{2}}{n-1}}=37.212 \mathrm{~mm}
$$

Koefisien variasi (coefficient of variation)

$C v=\frac{S}{\bar{X}}=\frac{37.212}{100.833}=0.369$

Koefisien Kemiringan (coefficient of skewness)

$$
\mathrm{Cs}=\frac{n \sum(X i-\bar{X})^{3}}{(n-1)(n-2) S^{3}}=\frac{15 \times 271883}{14 \times 13 \times 37.212^{3}}=0.435
$$

Koefisien Kemencengan(coefficient of curtosis)

$\mathrm{Ck}=\frac{n^{2} \sum(X i-\bar{X})^{4}}{(n-1)(n-2)(n-3) S^{4}}=\frac{15^{2} \times 4740781168}{14 \times 13 \times 12 \times 37.212^{4}}=0.170$

Berdasarkan perhitungan parameter statistik diatas, diperoleh nilai koefisien kemencengan $(\mathrm{Cs})=0 . .435$ dan nilai koefisien ketajaman $(\mathrm{Ck})$ $=0.170$. setelah itu dilakukan perhitungan uji kecocokan sebaran dengan memilih distribusi log pearson dengan syarat harga $\mathrm{Cs}=0-0.9$, sedangkan sebagai pembanding dipilih distribusi 
Studi Pengendalian Banjir Sungai Kalidawir Tulungangung gumbel yang memiliki harga $\mathrm{Cs}=1.139 \mathrm{dan} \mathrm{Ck}<$ 5.402 .

\subsection{Uji Kecocokan Sebaran}

\subsubsection{Uji Chi Kuadrat}

Jumlah data $(\mathrm{n})=15$

Jumlah kelas $(\mathrm{k})=1+3.322 \log (15)=4.92=5$

Jumlah kelas (k) digunakan

- Sub Kelompok I dengan $\mathrm{P} \leq 0.2$

- Sub Kelompok II dengan $0.2<\mathrm{P}<0.4$

- Sub Kelompok III dengan $0.4<\mathrm{P}<0.6$

- Sub Kelompok IV dengan $0.6<\mathrm{P}<0.8$

- Sub Kelompok V dengan $\mathrm{P} \geq 0.8$

[Sumber : Soewarno, 1995]

\subsubsection{Distribusi Pearson Log Pearson Tipe III} $\log X i=\log \bar{X}+\mathrm{K} \quad \mathrm{Sd} \log$ X......................(3.1)

Dari perhitungan analisa frekuensi diperoleh nilai $\log \bar{X}=2.0366$ dan $S d \log X=0.1648$. Persamaan dasar dengan menggunakan metode Log Pearson tipe III adalah $\log X=2.004+k$ (0.165),

Untuk $\mathrm{P}=0.2$

$\log X=2.004+\mathrm{k}(0.165)=2.004+(0.84 \quad \mathrm{x}$ $0.165)=2.142$

$\mathrm{X}=138.74 \mathrm{~mm}$

\section{Tabel 3.2 Perhitungan Chi Kuadrat} Distribusi Log Pearson Type III

\begin{tabular}{|c|c|c|c|c|c|}
\hline \multirow[t]{2}{*}{$\mathrm{Nc}$} & \multirow{2}{*}{$\begin{array}{c}\text { Nilai sub Batas } \\
\text { Kelompok }\end{array}$} & \multicolumn{2}{|c|}{ Jumlah data } & \multirow[b]{2}{*}{$(\mathrm{Oi}-\mathrm{Ei})^{2}$} & \multirow{2}{*}{\begin{tabular}{|c|}
$(\mathrm{Oi}-\mathrm{Ei})^{2}$ \\
$\mathrm{Ei}$
\end{tabular}} \\
\hline & & Oi & $\mathrm{Ei}$ & & \\
\hline 1 & $X<138.74$ & 3 & 3 & 0 & 0 \\
\hline 2 & $91.62<X<138.74$ & 4 & 3 & 1 & 0.333 \\
\hline 3 & $73.28<X<91.62$ & 2 & 3 & 1 & 0.333 \\
\hline 4 & $41.68<X<73.28$ & 2 & 3 & 1 & 0.333 \\
\hline 5 & $X<41.68$ & 0 & 3 & 9 & 3 \\
\hline & Total & 11 & 15 & & 4 \\
\hline
\end{tabular}

(Sumber: Hasil Perhitungan) memenuhi syarat.

\subsubsection{Uji Smirnov-Kolmogorov}

\subsubsection{Distribusi Log Pearson Tipe III}

Tabel 3.3 Hasil Uji Smirnov-Kolmogorov untuk Distribusi

\begin{tabular}{|c|c|c|c|c|c|c|}
\hline Tahun & $\mathrm{X}(\mathrm{mm})$ & $\mathrm{m}$ & $\mathrm{P}(\mathrm{X})$ & $\mathrm{P}^{\prime}(\mathrm{X})$ & $\mathrm{f}(\mathrm{t})$ & $\mathrm{D}$ \\
\hline 2000 & 2.237 & 1 & 0.063 & 0.938 & 1.414 & 0.061 \\
\hline 2004 & 2.158 & 2 & 0.125 & 0.875 & 0.937 & 0.085 \\
\hline 2005 & 2.158 & 3 & 0.188 & 0.813 & 0.937 & 0.046 \\
\hline 2006 & 2.123 & 4 & 0.250 & 0.750 & 0.727 & -0.045 \\
\hline 2002 & 2.099 & 5 & 0.313 & 0.688 & 0.576 & -0.078 \\
\hline 2001 & 2.099 & 6 & 0.375 & 0.625 & 0.576 & -0.042 \\
\hline 2003 & 1.984 & 7 & 0.438 & 0.563 & -0.119 & -0.019 \\
\hline 2010 & 1.969 & 8 & 0.500 & 0.500 & -0.211 & 0.004 \\
\hline 2008 & 1.954 & 9 & 0.563 & 0.438 & -0.299 & 0.055 \\
\hline 2009 & 1.902 & 10 & 0.625 & 0.375 & -0.618 & 0.117 \\
\hline 2013 & 1.835 & 11 & 0.688 & 0.313 & -1.022 & 0.140 \\
\hline 2011 & 1.796 & 12 & 0.750 & 0.250 & -1.257 & 0.186 \\
\hline 2012 & 1.789 & 13 & 0.813 & 0.188 & -1.305 & 0.191 \\
\hline 2007 & 1.788 & 14 & 0.875 & 0.125 & -1.311 & 0.205 \\
\hline 1999 & 1.744 & 15 & 0.938 & 0.063 & -1.574 & 0.226 \\
\hline
\end{tabular}

(Sumber: Hasil Perhitungan)

\subsection{Kesimpulan Analisa Frekuensi}

Tabel 3.4 Penentuan Distribusi yang Dipakai

\begin{tabular}{|c|c|c|}
\hline \multirow{2}{*}{ Uji } & \multicolumn{2}{|c|}{ Distribusi } \\
\cline { 2 - 3 } & Log Pearson III & Gumbel \\
\hline Uji Chi Kuadrat & 4.667 \\
\hline $\mathrm{X}^{2}$ hitung & 4.000 & 5.991 \\
\hline $\mathrm{X}^{2}$ tabel & 5.991 & Diterima \\
\hline Hipotesa & Diterima & 0.911 \\
\hline Uji S. Kolmogorov & 0.34 \\
\hline D max & 0.226 & Tidak \\
\hline D kritis & 0.34 & Diterima \\
\hline \multicolumn{2}{|c}{} \\
Hipotesa & Diterima &
\end{tabular}

(Sumber: Hasil Perhitungan)

Dari tabel di atas dapat disimpulkan bahwa nilai $\chi \mathrm{kr}=5.991$ dan $\chi^{2}=4$ Karena $\chi^{2}<\chi \mathrm{kr}$ maka persamaan log pearson tipe III yang diperoleh 


\subsection{Perencanaan Normalisasi Penampang Melintang Sungai}

\subsubsection{Normalisasi Bagian Hulu}

Normalisasi Penampang Sungai kalidawir dilakukan mengingat kapasitas Kali Kalidawir yang tidak bisa menampung debit banjir rencana. Normalisasi dilakukan sesuai crosssection pada tahun 2002 dengan melakukan pengerukan sedimen. Berikut rencana penampang melintang sungai Kalidawir direncanakan berbentuk trapesium tunggal dengan spesifikasi sebagai berikut:

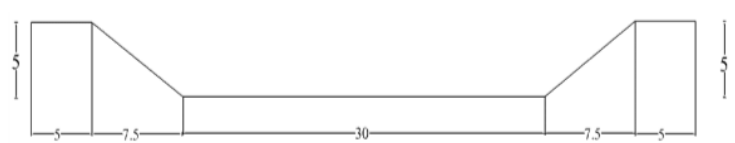

Gambar 3.1 Rencana Penampang Sungai Kalidawir Bagian Hulu

$\begin{aligned} \text { Lebar alur sungai } & =30 \text { meter } \\ \text { Kemiringan tanggul rencana } & =1: 1.5 \\ \text { Kemiringan sungai rencana } & =\text { Bagian Hulu } \\ & =0.01\end{aligned}$

\section{$=$ Bagian Hulu-Tengah=0.005}

Panjang alur sungai rencana $=$ Bagian Hulu $=4000 \mathrm{~m}$

$=$ BagianHulu-Tengah $=2325$

Koefisien manning $=0.0275$ (Dasar saluran tanah dan tebing plengsengan beton).

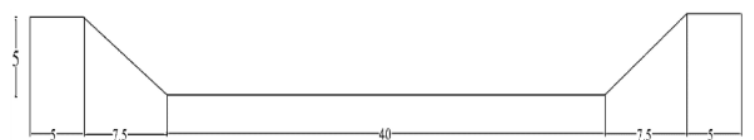

Gambar 3.2 Rencana Penampang Sungai Kalidawir Bagian Tengah

Lebar alur sungai

Kemiringan Tanggul rencana

Kemiringan sungai rencana

Tengah $=0.001$

Panjang alur sungai rencana $=$ Bagian Tengah $=2442.5 \mathrm{~m}$

Koefisien manning $=0.0275$ (Dasar saluran tanah dan tebing plengsengan beton),
Besanya nilai kapasitas penampang tadi kemudian diperoleh nilai kecepatan (v) sebesar $2.5 \mathrm{~m}^{3} /$ detik.

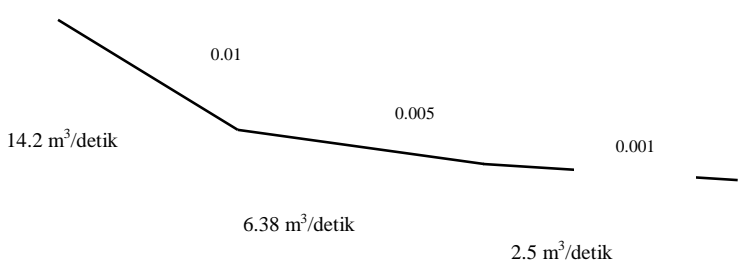

\section{Gambar 3.3 Kemiringan Sungai Rencana}

Dengan melihat gambar 3.3 kemiringan sungai rencana, dapat dilihat bahwa terjadi perbedaan kecepatan antara sungai Kalidawir bagian hulu dan transisi. Oleh karena itu perlu diberi bangunan pengaman sungai dalam mengurangi degradasi-agradasi sungai, pengaman lereng, ground sill, analisa hidrolika (perubahan penampang) maupun bangunan pengatur sungai lainnya.

\subsection{Perencanaan Krib}

Direncanakan Direncanakan krib dari tiang pancang beton dengan arah tegak lurus alur memiliki spesifikasi sebagai berikut:

Lebar penampang sungai yang tidak terhalang air aliran air $=30$ meter

Panjang Krib =7.5 meter

Jarak antar tiang pancang $=-1.5 \mathrm{~m}$ (di bagian bantaran $)=-1.5 \mathrm{~m}($ di bagian tengah $)$

Dimater tiang pancang $(d)=0.3$ meter

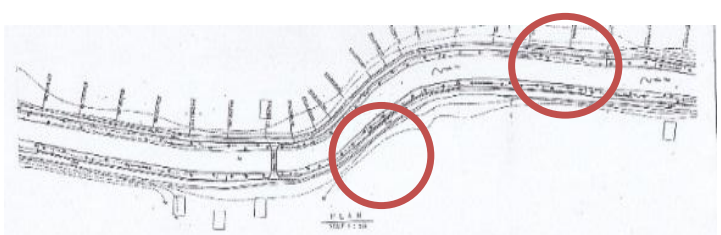

\section{Gambar 3.8 Lokasi Perencanaan Krib}

Pada perencanaannya, ditentukan terlebih dahulu lebar penampang sungai yang tidak terhalang aliran airnya kemudian ditentukan panjang krib lolos air. Untuk krib bantaran digunakan jarak 1.5 meter supaya dibagian alur utamanya hambatannya tidak terlalu besar, pada puncak krib di bantaran tinggi pancang beton direncanakan sebesar $10 \mathrm{~cm}$ diatas muka air banjir (MAB). 


\begin{tabular}{|l|l|l|l|l|}
\hline No. & $\mathrm{R}(\mathrm{m})$ & $\mathrm{B}(\mathrm{m})$ & $\mathrm{R} / \mathrm{B}<10$ & Keterangan \\
\hline 1 & 97.155 & 16.019 & 6.065 & tidak aman \\
\hline 2 & 101.775 & 19.922 & 5.108 & tidak aman \\
\hline 3 & 92.023 & 19.219 & 4.788 & tidak aman \\
\hline 4 & 101.775 & 19.222 & 5.294 & tidak aman \\
\hline 5 & 85 & 21.3 & 3.990 & tidak aman \\
\hline 6 & 32.792 & 16.86 & 1.944 & tidak aman \\
\hline
\end{tabular}

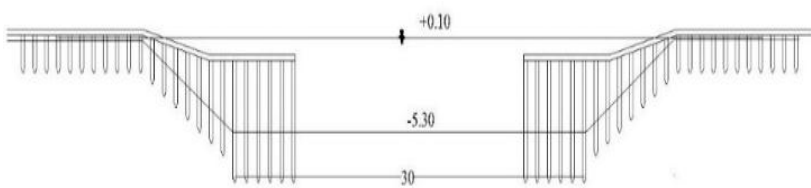

\section{Gambar 7.9 Potongan Memanjang Krib Beton pada Sta. 800}

\subsection{Perencanaan Pengaman Tikungan Alur Sungai}

Pada sungai Kalidawir bagian tengah terdapat beberapa bagian yang bentuknya berupa tikungan, oleh karena itu diperlukan analisa kekritisan tikungan dengan cara menganalisa perbandingan jari-jari lengkungan tikungan $\mathrm{R}$ dan lebar penampang saat tikungan (B),dengan syarat $\mathrm{R} / \mathrm{B}<10$. Dengan melihat gambar 6.6-7.2 kemudian dilakukan perhitungan kekritisan $\mathrm{t}$ yang ditabelkan seperti gambar dibawah:

Tabel 4.26 Harga Kekritisan Penampang Sumber: Hasil Perhitungan

\section{Gambar 3.9 Lokasi Perencanaan Krib}

Perhitungan kecepatan aliran dengan menggunakan krib:

Krib pada daerah Sta.802, terdapat 3 baris krib dengan

jarak antar krib 25 meter. Berikut data-data perencanaan:

Debit Banjir rencana $(\mathrm{Q} 25)=286.24 \mathrm{~m}^{3} /$ detik

Elevasi Muka Air $=+0.05$,

elevasi dasar saluran $=-5.25 \rightarrow \mathrm{h}=5.30$ meter

Luas Penampang saluran $\left(\mathrm{A}_{0}\right)=187.5 \mathrm{~m}^{2}$

Lebar penampang yang tidak terhalang aliran air $=15$ meter

Diameter tiang pancang $(\mathrm{d})=0.3$ meter

Panjang Tiang Pancang $=12$ meter

Dalam 1 baris terdapat 1 group tiang pancang, masing-masing terdapat 8 buah tiang pancang dengan jarak 1.5 meter.

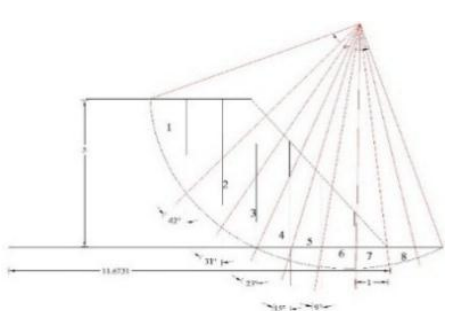

\section{Gambar 7.7 Irisan Bidang Longsor}

Tabel 4.27 Perhitungan Stabilitas Lereng

\begin{tabular}{|c|c|c|c|c|c|c|}
\hline Irisan & Luas & $\gamma(\mathrm{t} / \mathrm{m} 2)$ & $\mathrm{W}(\gamma \cdot \mathrm{A})$ & Sudut $(\alpha)$ & $\mathrm{T}(\mathrm{W}$ sina $)$ & $\mathrm{N}(\mathrm{W} \cos \alpha \times \operatorname{tg} \alpha)$ \\
\hline 1 & 2.01 & 1.68 & 3.38 & 42 & 2.26 & 2.26 \\
\hline 2 & 3.04 & 1.68 & 5.11 & 31 & 2.63 & 2.63 \\
\hline 3 & 2.92 & 1.68 & 4.90 & 23 & 1.914 & 1.914 \\
\hline 4 & 2.30 & 1.68 & 3.86 & 15 & 0.999 & 0.065 \\
\hline 5 & 1.64 & 1.68 & 2.76 & 9 & 0.43 & 0.02 \\
\hline 6 & 0.84 & 1.68 & 1.41 & -15 & -0.36 & -0.365 \\
\hline 7 & 0.44 & 1.68 & 0.74 & -23 & -0.289 & -0.289 \\
\hline \multicolumn{5}{|c|}{ jumlah } & 7.584 & 6.235 \\
\hline
\end{tabular}

Dengan nilai:

Sumber : Perhitungan

$\mathrm{L}=\frac{\theta}{360} 2 \pi R=\frac{87}{360} 2 \pi 7.65=11.61$ meter

$\gamma$ dry $=0.56 \mathrm{gr} / \mathrm{cm} 3,(\Phi)=6.28$,

Tegangan Prakonsolidasi ( $\sigma$ prakonsolidasi) $(\mathrm{kg} / \mathrm{cm} 2)=0.72$

$$
\begin{aligned}
& \mathrm{SF}=\frac{\sum \boldsymbol{C i} . \boldsymbol{L i}+\sum(\boldsymbol{N} \boldsymbol{i} * \boldsymbol{t a n} \phi)}{\sum(\boldsymbol{T i})} \frac{(0.72 \times 11.61)+6.235}{7.584} \\
& =1.925 \text { (Aman) }
\end{aligned}
$$

Dengan demikian dinding revetmen dapat menahan gaya longsor yang terjadi. 


\subsection{Perencanaan Ambang (Ground Sill)}

Ground sill berfungsi untuk mengendalikan ketinggian dan kemiringan dasar sungai, agar dapat mengurangi atau menghentikan degradasi sungai (Sosrodarsono, 2009). Bangunan ini juga dibangun untuk menjaga agar dasar sungai tidak turun terlalu berlebihan. Perencanaan ambang :

Tinggi ambang

$\mathrm{L}=(1 / \mathrm{n}-1 / \mathrm{m}) \mathrm{h}=(1.5-2.0) \mathrm{l} / \mathrm{h}$

Dimana :

$\mathrm{L}=$ jarak antara ambang $(\mathrm{m})$

$\mathrm{h}=$ tinggi ambang $(\mathrm{m})$

$\mathrm{n}=$ kemiringan dasar sungai

$\mathrm{m}=$ tingkatan perencanaan dasar sungai

$\mathrm{b}=$ lebar sungai $(\mathrm{m})$

Dengan melihat lebar sungai rencana 40 meter. Maka diperoleh nilai $\mathrm{L}=(1.5 \times 2.7) \times 0.50=2$ meter. Direncanakan tinggi ambang $(\mathrm{D})=50 \mathrm{~cm}$, $\mathrm{h}=20 \mathrm{~cm}, \mathrm{H}=$ Total tinggi tekanan $=\mathrm{D}+\mathrm{h}=70$ $\mathrm{cm}$,

$\mathrm{h}_{\mathrm{f}}=$ Kehilangan tinggi tekanan akibat geseran

$=\mathrm{C} *(\mathrm{D} / \mathrm{h}) * \mathrm{H}=0.002 *(0.5 / 0.2) * 0.7=0.4025$

$h_{1}{ }^{3}-\left(H-h_{1}\right) h_{1}{ }^{2}+\frac{q^{2}}{2 g}=0$

$h_{1}{ }^{3}-\left(70-h_{1}\right) h_{1}{ }^{2}+\frac{286.24^{2}}{2 \times 9.8}=0$

$h_{1}{ }^{3}-70 h_{1}{ }^{2}-h_{1}{ }^{3}+\frac{286.24^{2}}{2 \times 9.8}=0$

$70 h_{1}{ }^{2}=4180.273$

$\mathrm{h}_{1}^{2}=59.712$

$\mathrm{h}_{1}^{2}=7.73 \mathrm{~cm}$

Besarnya $h_{2}$ dihitung berdasarkan rumus berikut:

$h_{2}=\sqrt{\frac{h_{1}^{2}}{4}}+\sqrt{\frac{2 x 28624^{2}}{4}}+\sqrt{\frac{h 1}{4}}$
$h_{2}=\sqrt{\frac{7.73^{2}}{4}}+\sqrt{\frac{(2 x 286.24)^{2}}{4}}+\sqrt{\frac{7.73}{4}}$ $=3.865+2+1.39=+7.255$

\section{Analisa Hidrolika Perubahan Penampang}

Diketahui suatu saluran berpenampang trapesium melebar lambat laun dari suatu lebar 18.23 meter menjadi 30 meter. Kedalaman air di hulu diasumsikan sedalam 3.52 meter dan kecepatan

aliran $14.2 \mathrm{~m} /$ detik. Perkirakan kedalaman aliran setelah perlebaran.

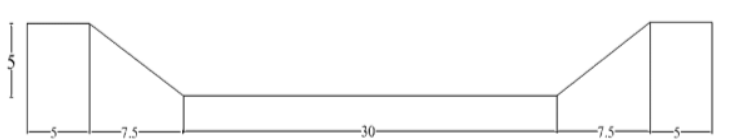

Gambar 7.3 Rencana Penampang Sungai Kalidawir

\section{Bagian Hulu}

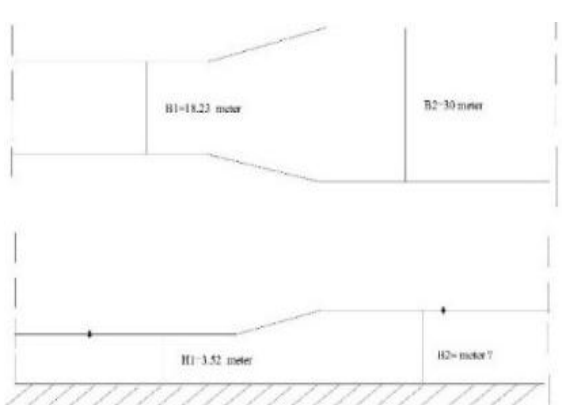

\section{Gambar 7.4 Penampang memanjang dan tampak atas saluran dalam}

Penyelesaian :

Untuk suatu penampang trapesium luas dan kedalamannya hidraulik nya adalah:
$A=(B+z h) h$
$D=\frac{(B+Z h) h}{(B+2 Z h)}$

Dalam soal ini diketahui bahwa lebar $b=18.23$, $\mathrm{h}=3.52$ meter dan kemiringan tebing 1.5, maka:

$A=(18.23+1.5 h) h$

$D=\frac{(18.23+1.5 h) h}{(18.23+3 h)}=\frac{(1+h) h}{(1+2 h)}$

$D=\frac{Q}{A}=\frac{286.24}{18.23+1.5 h}=12.17$

$\mu=\frac{Q}{A}=\frac{286.24}{18.23+1.5 h}$

$\frac{\mu^{2}}{2 g}=\frac{D}{2}$

$\mathrm{m}^{3} /$ detik

$\mathrm{q}=\frac{286.24}{18.23}=15.7 \mathrm{~m} 2 /$ detik

$F_{R}=\frac{u_{1}}{\sqrt{g D}}=\frac{14.2}{\sqrt{9.8 \times 12.17}}=1.3$

Menurut Anggrahini(2005), apabila $\frac{d B}{d x}>0$ dan $\mathrm{F}_{\mathrm{R}}>1$ atau $\left(1-\mathrm{F}_{\mathrm{R}}{ }^{2}\right)$, maka $\frac{d h}{d x}$ menjadi lebih kecil daripada nol, hal ini berarti kedalaman aliran 
Studi Pengendalian Banjir Sungai Kalidawir Tulungangung

berkurang di arah x. Karena tidak ada perubahan elevasi dasar saluran dan kehilangan energi diabaikan maka energi spesifik di hulu $\left(\mathrm{E}_{1}\right)$ sama dengan energi spesifik di hilir $\left(\mathrm{E}_{2}\right)$.

\section{DAFTAR PUSTAKA}

[1] Anggrahini.2005. Hidrolika Saluran Terbuka.ITS Press:Surabaya.

[2] Kodoatie,Robert\&Sugiyanto.2002.Banjir:Be berapa penyebab dan Metode Pengendaliannya dalam Perspektif Lingkungan. Semarang : Pustaka Pelajar.

[3] Anwar, Nadjaji. 2012. Rekayasa Sumber Daya Air. Surabaya: ITS Press.

[4] Soemarto,C.D.1999. Hidrologi Teknik.Jakarta: Erlangga

[5] Sosrodarsono, Suyono \& Tominaga. 1985. Perbaikan dan Pengaturan Sungai. Jakarta:Pradnya Paramita

[6] Suwarno.1995. Hidrologi Aplikasi Model Statistik untuk Analisa Data Jilid I. Bandung: Nova.

[7] Sholeh, M.Diktat Hidrologi. Surabaya : FTSP ITS

[8] Yang, Chih Ted.1996. Sediment Transport Theory and Practice. Mc.Graw Hill International Edition Civil Engineering Series.

[9] Sosrodarsono.1987. Teknik Sungai. Jakarta: Pradnya Paramita

[10] Soesanto, Soekibat Roedy. Waduk dan PLTA.

[11] Dian Ayu Ratnasari. Studi Pengendalian Banjir Sungai Kalidawir.2014. 